Journal of International Medical Research \& Health Sciences, 2021, 1(1): 29-38

Research

\title{
The perception on team based learning teaching method among physiotherapy and occupational therapy students
}

\author{
Fernando HCBP ${ }^{1}$, Dharmapriya $\mathrm{MKJKB}^{2 *}$, Kamalaraj $\mathrm{K}^{3}$ \\ ${ }^{1}$ School of physiotherapy and occupational therapy, Srilanka. \\ ${ }^{2}$ Department of Basic Sciences, Faculty of Allied Health Sciences, General Sir John Kotelwala \\ Defence University, Srilanka \\ ${ }^{3}$ Department of Musculoskeletal Sciences, University hospital General Sir John Kotelwala \\ Defence University, Srilanka \\ *Corresponding E-mail: jenadpst@gmail.com
}

\begin{abstract}
Background: Team-based learning (TBL) is a well-defined, student-centred instructional strategy that purportedly engages students in active learning and critical thinking. TBL makes students to prepare with information learned from completing clearly communicated, pre-class assignments to solve real-world problems in permanent, predetermined work teams. Objective: This study was developed in order to determine the perception on TBL among physiotherapy and occupational therapy students of school of physiotherapy and occupational therapy. Methodology: This was a descriptive cross-sectional study. Sample size was 60 with 30 students from each physiotherapy and occupational therapy group. Data collection was done after a TBL session on respiratory mechanisms. Data collection was done using three self-administered questionnaires. They are socio-demographic questionnaires, Team-Based Learning Subscale (TBLS) which assessed student's preference on TBL and students satisfaction subscale (SSS) in which students feeling /attitudes on TBL was assessed. Results: Both TBLS and SSS showed positive responses. Results of TBLS recorded as 2.29\%-3.91\% above the natural score 48 giving positive preference on TBL.SSS recorded as $15.07 \%-16.41 \%$ above the neutral score 27 giving positive feelings/attitudes on TBL among both physiotherapy and occupational therapy students groups. There was not any significant difference of TBLS and SSS (P value $>0.05)$ in two groups. Further, there was a significant correlation (P value $<0.05)$ between TBLS and SSS in occupational therapy student group and whole population but not in physiotherapy student group. Conclusion: There was a positive perception among physiotherapy and occupational therapy students on TBL with significant linear relationship among preference and attitudes/feeling in TBL.
\end{abstract}

Keywords: Team based learning, physiotherapy, occupational therapy, socio-demographic, attitudes/feelings.

Received: 15 May, 2021

Accepted: 31 May, 2021

Published: 07 June, 2021

\section{Introduction}

Team-based learning (TBL) is a well-defined, student-centred instructional strategy developed by Dr. Larry Michaelsen that purportedly engages students in active learning and critical thinking. Students in TBL courses come prepared with information learned from completing clearly communicated, pre-class assignments to solve real-world problems in permanent, predetermined work teams [14]. Through regular assessments, both as individuals and as a team, students are given frequent, immediate feedback on the quality of their performance. Absorbing TBL to classroom requires a change in teaching and learning process by both teacher and student. There are main 4 principles 
of implementing TBL in the classroom [14].

The first principle of a group that the group must be carefully formed and managed. Permanence, diversity of resources, and ability of clear communication are the key features of team or group formation. Team dynamics, expectations, and trust to develop as groups are governed by permanence [10]. Instructors find easy to stratify students into teams due to diversity of resources as well as education, experience, and cultural background. Clear communication helps in absorbing their role within the team. All action must be taken in order to prevent communication disturbance within the group.

Accountability is the second principle of team-based learning is that students must be accountable for individual and teamwork. Accountability is vital in team-building and survival. In addition to the quality of the team's work, individual team members must be accountable for their pre-class preparation, classroom learning, and constructive team participation [10].

The third fundamental principle is feedback that is students must receive frequent and timely feedback from faculty members. In this process, feedback is provided in two ways. For individuals, it is provided through the readiness assessment test for individuals (iRAT), for teams it is provided by readiness assessment test for teams (tRAT). Some instructors also provide feedback to students as part of the peer-review process. Assignment design is the fourth principle that is team application exercises must promote learning and team development. Both teacher and students have to play an interactive role on that.

The instructional unit in team based learning is implemented in 3 phases: preparation, readiness assurance, and application [17].

Preparation: Unlike a traditional lecture-driven course, the team-based learning instructional unit begins before students come to class. Students should possess background knowledge. This pre-class learning is directed by the instructor through a preparation assignment for each unit. Critical to the students' successful pre-class learning are clear, concise learning objectives written by the instructor to guide the student through the new instructional material. To allow students enough time to engage the pre-class material, the assignment should be given well in advance. Supplementary materials, such as pre-recorded lectures, slide sets, or practice exercises, may be included that help students to focus on the learning objectives.

Readiness assurance: It would be difficult to engage students in learning material prior to class in order to be adequately prepared to participate in class. In fact, one of the advantages of team-based learning is that the readiness assurance process results in excellent class attendance. The iRATs are collected and then the same test is distributed to the teams and each team is given time to discuss and select the best answers for the tRAT. Once completed, tRATs are collected by the instructor, who then transitions into a discussion facilitator role [15].

Application of Key Concepts: In the team-based learning classroom, the highest level of learning occurs during the application exercises. Developing the application exercises to target the skills, knowledge, and values for the learning unit helps the instructor use the classroom time efficiently and assigns appropriate pre-class material for the students [18].

\section{Methodology}

This was a descriptive cross-sectional study done at School of Physiotherapy and Occupational therapy Colombo Sri Lanka. The study population was the students who follow the diploma in physiotherapy and Occupational therapy course batch XXXV at School of Physiotherapy and Occupational therapy, Colombo -Sri Lanka. A sampling 
technique was not used to select the study subjects since the total study population is enrolled in the study. Inclusion of all the males and females batch XXXV students of school of physiotherapy and occupational therapy students who are not fit physically and mentally during the data collection were excluded from the study.

\section{Data collection tools}

\section{a. Socio-demographic questionnaire}

This questionnaire contains 10 questions related to participant's socio demographics characteristics.

b. $\quad$ Team based learning subscale (TBLS) [13]

This questionnaire assesses the preferences on TBL as a fraction of perception on TBL. It contains 16 questions. Participants have to select their answers according to 5 items. And they strongly disagree, disagree, neither disagree or agree, agree and strongly agree scale.

c. Student satisfaction subscale (SSS) [13]

This questionnaire assesses the attitudes/feelings on TBL as a fraction of perception on TBL. It contains 9 questions. Participants have to select their answers according to 5 items. And they strongly disagree, disagree, neither disagree or agree, agree and strongly agree.

\section{Data collection method}

Participants were selected according to the inclusion and exclusion criteria. The study was fully explained to the participants and their written consent was obtained. Students were divided into 6 groups each group consisted 10 members. Respiratory mechanism study guide which includes aims, learner's outcome, content areas, time allocation, assessment and evaluation and references was given to each group for one week pre-class activity.

10 multiple choice questions and 1 short essay question were given as an individual reassurance task for 30 min. After 30 min individual reassurance task was collected and then the same test was distributed to the teams and each team was given time to discuss and select the best answers for the team reassurance task. Once completed, team reassurance task was collected by the instructor and conducted a mini-lecture. Further, students were able to understand the clinical application of respiratory mechanism during intensive care unit practice and can be able to treat the patient confidently.

At the end of that TBL session the three self-administrated questionnaires were given to them. Socio-demographic characteristics were recorded using socio-demographic questionnaire. Student's preference on TBL was recorded using Team based learning subscale (TBLS). Finally, student's feelings and attitudes on TBL were recorded using student satisfaction subscale (SSS).

Name of the participants was not included. Data from TBLS were kept blind from data from SSS.

\section{Data analysis}

For both TBLS and SSS scale for the 5 items was following [13].

\begin{tabular}{|l|c|}
\hline Item & Score \\
\hline Strongly disagree & 1 \\
\hline Disagree & 2 \\
\hline Neither agree or disagree(neutral) & 3 \\
\hline Agree & 4 \\
\hline Strongly agree & 5 \\
\hline
\end{tabular}


For TBLS total score was 80 as it contains 16 questions. Each participant score was recorded out of 80.48 out of 80 was taken as the neutral value of TBLS [13]. So above 48 out of 80 was taken as a positive response.

For SSS total score was 45 as it contains 9 questions .Each participant's score was recorded out of 45.27 out of 45 was taken as the neutral value for SSS [13]. So above 27 out of 45 was taken as a positive response.

Quantitative and qualitative data will be analyzed by using Statistical Package for Social Science (SPSS) version 22. $\mathrm{P}<0.05$ considered as a significant.

\section{Results}

Response percentage of the study was $100 \%$. There were 60 subjects included in study. From them 30 were physiotherapy students and 30 were occupational therapy students.

\section{Gender distribution among study population}

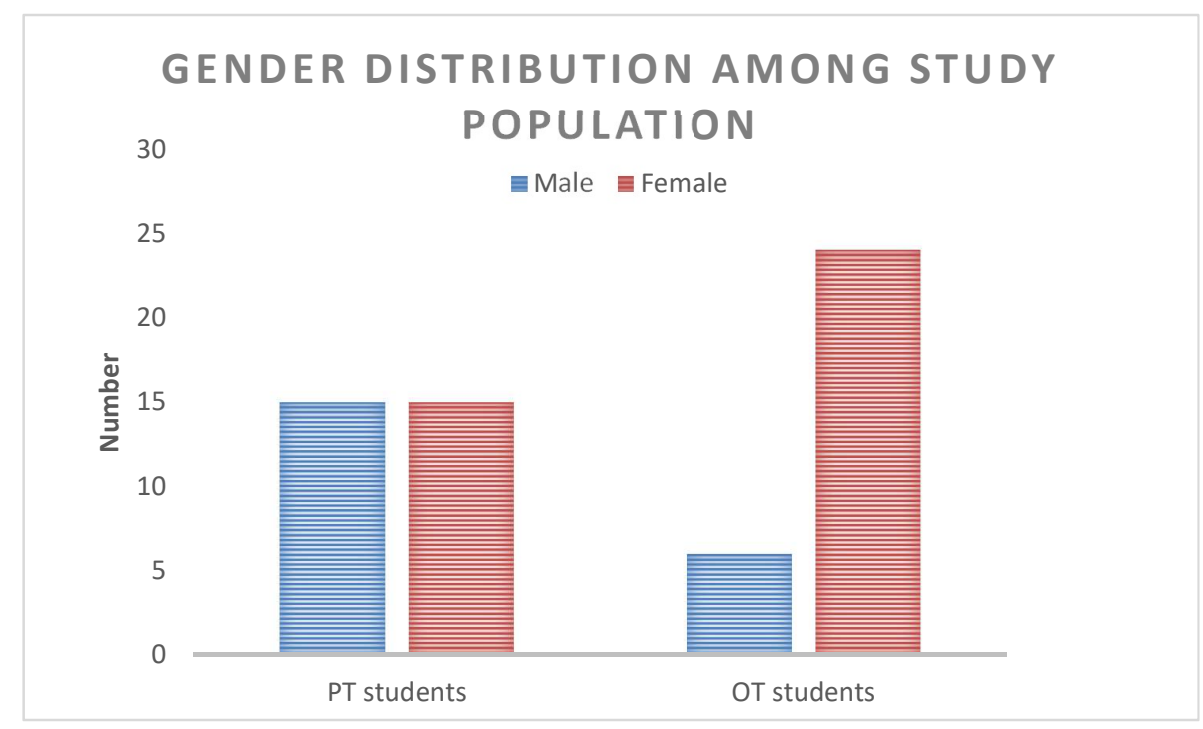

Figure 01: Gender distribution among the study population

Figure 01 shows the gender distribution among the study population

\section{Socio-demographic characteristics among study population}

When considering about socio-demographic characteristics among the study population several main characteristics were emphasized. They were age, civil status, ethnicity, mother tongue, service type, and previous academic exposure (Table 01). Age distribution was normal in both groups. Physiotherapy students showed high mean age in comparison to occupational therapy students. Civil status showed two subcategories. Those were unmarried and married. In both groups unmarried percentage was high. And there were no any married subjects recorded in occupational therapy students. Sinhalese, Sri Lankan Tamils and Muslims were main subcategories of ethnicity. In both groups most prominent ethnicity was Sinhalese and least prominent one was Muslims. When considering about the mother tongue Sinhala was the dominant language in both groups. Civil and military were the two subcategories of service type. In physiotherapy students, civil service type was the dominant one and the military was the least one. But there were no 
any military subjects among occupational therapy group. Finely previous higher education exposure prior to the respective physiotherapy or occupational therapy diploma was recorded. In physiotherapy group $60 \%$ were doing higher education prior to the diploma from them $87.5 \%$ were doing degree and $12.5 \%$ were doing diploma. The time period they have spent to higher education was $10.53+6.09$ in months. In occupational therapy group $37.7 \%$ were doing higher education prior to the occupational therapy diploma. From them $66.67 \%$ were doing degree. $33.33 \%$ were doing diploma. The time period they have spent to higher education was $13.67+7.46$ in months.

Table 01: Socio-demographic characteristics among study population

\begin{tabular}{|c|c|c|}
\hline Characteristic & Physiotherapy Students & $\begin{array}{c}\text { Occupational therapy } \\
\text { Students }\end{array}$ \\
\hline Age (Mean+SD years) & $\begin{array}{l}\text { Male }(26.53 \pm 2.36) \\
\text { Female }(24.53 \pm 2.10)\end{array}$ & $\begin{array}{l}\text { Male }(23.33 \pm 0.82) \\
\text { Female }(23.50 \pm 1.01)\end{array}$ \\
\hline CIVIL Status & $\begin{array}{l}\text { Unmarried } 76.7 \% \\
\text { Married } 23.3 \%\end{array}$ & $\begin{array}{l}\text { Unmarried } 100 \% \\
\text { Married } 0 \%\end{array}$ \\
\hline Ethnicity & $\begin{array}{l}\text { Sinhalese } 90 \% \\
\text { Sri Lankan Tamils } 6.7 \% \\
\text { Muslims } 3.3 \%\end{array}$ & $\begin{array}{l}\text { Sinhalese } 85.3 \% \\
\text { Tamils } 13.3 \% \\
\text { Muslims } 3.3 \%\end{array}$ \\
\hline Mother Tongue & $\begin{array}{l}\text { Sinhala } 90 \% \\
\text { Tamil } 10 \%\end{array}$ & $\begin{array}{l}\text { Sinhala } 83.3 \% \\
\text { Tamil } 16.7 \%\end{array}$ \\
\hline Service Type & $\begin{array}{l}\text { Civil } 60 \% \\
\text { Military } 40 \%\end{array}$ & $\begin{array}{l}\text { Civil } 100 \% \\
\text { Military } 0 \%\end{array}$ \\
\hline $\begin{array}{l}\text { Previous higher } \\
\text { education exposure } \\
\text { Expended time in } \\
\text { months } \\
\text { (Mean +SD) }\end{array}$ & $\begin{array}{l}\text { Yes } 60 \% \\
\text { Degree } 87.5 \% \\
\text { Diploma } 12.5 \% \\
\text { No } 40 \% \\
10.53 \pm 6.09\end{array}$ & $\begin{array}{l}\text { Yes } 37.7 \% \\
\text { Degree } 66.67 \% \\
\text { Diploma } 33.33 \% \\
\text { No } 62.3 \% \\
13.67 \pm 7.46\end{array}$ \\
\hline
\end{tabular}

\section{Results of TBLS and SSS}

Both score values shows normal distribution among the study population.

Table 02: Test results on Team-Based Learning Subscale and Student Satisfaction Subscale

\begin{tabular}{|l|c|l|c|}
\hline Scale & $\begin{array}{c}\text { (Mean } \pm \text { SD }) \text { in } \\
\text { physiotherapy } \\
\text { students }\end{array}$ & $\begin{array}{c}\text { (Mean+SD ) in } \\
\text { occupational } \\
\text { therapy students }\end{array}$ & $\begin{array}{c}\text { (Mean } \pm \text { SD ) in } \\
\text { whole } \\
\text { population }\end{array}$ \\
\hline $\begin{array}{l}\text { Team-Based } \\
\text { subscale }\end{array}$ & $51.13 \pm 4.61$ & $49.83 \pm 7.40$ & $50.48 \pm 6.15$ \\
\hline $\begin{array}{l}\text { Student } \\
\text { satisfaction } \\
\text { scale }\end{array}$ & $31.43 \pm 2.80$ & $31.07 \pm 3.49$ & $31.25 \pm 3.14$ \\
\hline
\end{tabular}


Mean values of both scales had been recorded above the neutral values of each scale.

\section{Comparison of TBLS and SSS among physiotherapy and occupational therapy students}

Table 03: Comparison of test results on Team-Based Learning Subscale and Student Satisfaction Subscale

\begin{tabular}{|l|l|l|l|}
\hline Scale & $\begin{array}{c}\text { (Mean+SD ) in } \\
\text { physiotherapy } \\
\text { students }\end{array}$ & $\begin{array}{c}\text { (Mean+SD ) in } \\
\text { occupational } \\
\text { therapy students }\end{array}$ & P value \\
\hline $\begin{array}{l}\text { Team-Based } \\
\text { subscale }\end{array}$ & $51.13 \pm 4.61$ & $49.83 \pm 7.40$ & 0.418 \\
\hline $\begin{array}{l}\text { Student } \\
\text { satisfaction } \\
\text { scale }\end{array}$ & $31.43 \pm 2.80$ & $31.07 \pm 3.49$ & 0.655 \\
\hline
\end{tabular}

Two sample $t$ test was used to compare the mean values of TBLS and SSS among physiotherapy and occupational therapy students. $\mathrm{P}$ value $(>0.05)$ did not show any significant difference in results of Team-Based subscale and Student satisfaction Scale among two groups.

\section{Correlation between TBLS and SSS in each group}

Table 04: Correlation between test results on Team-Based Learning Subscale and Student Satisfaction Subscale

\begin{tabular}{|l|l|l|l|}
\hline & $\begin{array}{c}\text { In physiotherapy } \\
\text { students }\end{array}$ & $\begin{array}{c}\text { In occupational } \\
\text { therapy students }\end{array}$ & $\begin{array}{c}\text { In whole } \\
\text { population }\end{array}$ \\
\hline P Value & 0.437 & 0.010 & 0.005 \\
\hline r Value & 0.148 & 0.46 & 0.361 \\
\hline
\end{tabular}

Pearson correlation test was used to measure the correlation of results of same test between two groups. Results suggested a significant positive moderate correlation between TBLS and SSS among occupational therapy groups and whole population. It also showed insignificant positive correlation in physiotherapy group.

\section{Correlation TBLS and SSS}

Table 05: Correlation of same test results between physiotherapy and occupational therapy students

\begin{tabular}{|l|l|l|}
\hline & \multicolumn{1}{|c|}{$\begin{array}{c}\text { Team-Based Learning } \\
\text { subscale }\end{array}$} & \multicolumn{1}{c|}{$\begin{array}{c}\text { Student satisfaction } \\
\text { Subscale }\end{array}$} \\
\hline P Value & 0.424 & 0.353 \\
\hline r Value & -0.152 & -0.176 \\
\hline
\end{tabular}

Pearson correlation test was used to measure correlation of results of same test between two groups. Result suggested insignificant negative correlation on Team-Based subscale and student satisfaction scale among two groups.

7. Correlation of age and previous higher educational exposure in physiotherapy student group

Table 06: Correlation of age and previous higher educational exposure in physiotherapy students

\begin{tabular}{|l|c|c|}
\hline Variable & $\begin{array}{c}\text { Team-Based Learning } \\
\text { subscale }\end{array}$ & $\begin{array}{c}\text { Student satisfaction } \\
\text { Subscale }\end{array}$ \\
\hline
\end{tabular}




\begin{tabular}{|l|l|l|l|l|}
\hline & $\begin{array}{l}\mathbf{P} \\
\text { Value }\end{array}$ & $\begin{array}{l}\mathbf{r} \\
\text { Value }\end{array}$ & $\begin{array}{l}\mathbf{P} \\
\text { Value }\end{array}$ & $\begin{array}{l}\text { r } \\
\text { Value }\end{array}$ \\
\hline Age & 0.882 & -0.028 & 0.788 & 0.051 \\
\hline $\begin{array}{l}\text { Previous higher } \\
\text { educational exposure }\end{array}$ & 0.191 & 0.333 & 0.781 & -0.073 \\
\hline
\end{tabular}

Pearson correlation test was used to measure correlation of age and previous higher educational exposure with test results. $\mathrm{P}$ value and $\mathrm{r}$ value did not suggest any significant correlation among those variables

\section{Correlation of age and previous higher educational exposure in occupational therapy student group}

Table 07: Correlation of age and previous higher educational exposure in occupational therapy students

\begin{tabular}{|c|c|c|c|c|}
\hline \multirow[t]{2}{*}{ Variable } & \multicolumn{2}{|c|}{ Team-Based subscale } & \multicolumn{2}{|c|}{$\begin{array}{c}\text { Student satisfaction } \\
\text { scale }\end{array}$} \\
\hline & $\begin{array}{l}P \\
\text { Value }\end{array}$ & r Value & $\begin{array}{l}P \\
\text { Value }\end{array}$ & $\begin{array}{l}\text { r } \\
\text { Value }\end{array}$ \\
\hline Age & 0.313 & 0.191 & 0.748 & 0.599 \\
\hline $\begin{array}{l}\text { Previous higher } \\
\text { educational exposure }\end{array}$ & 0.265 & 0.350 & 0.781 & 0.169 \\
\hline
\end{tabular}

Pearson correlation test was used to measure correlation of age and previous higher educational exposure with test results. $\mathrm{P}$ value and $\mathrm{r}$ value did not suggest any significant correlation among those variables.

\section{Discussion}

\section{Socio-demographic characteristics}

Both groups showed similar distribution of socio-demographic characteristics (Age, Ethnicity, mother tongue, civil status, service type, and previous academic exposure). Socio-demographic characteristics show influence in teaching and learning activities [18]. But in this study there was no significant difference of socio-demographic characteristics among physiotherapy and occupational therapy students. Hence results of the study did not affect by any kind of dissimilarities of socio-demographic characteristics among two groups.

\section{Perception on Team-based learning}

Student perception was consisting with preferences for any given academic activity and positive feelings and attitudes towards a course format [13]. TBLS assessed the preference for any given academic activity. SSS asses the positive feeling and attitude toward a course format. All students from both groups reported positive scores on both TBLS (2.29\%-3.91\% above the neutral score) and SSS (15.07\%-16.41\% above the neutral score). Results of the study suggested slight preference and positive/good attitude\& feeling towards TBL in physiotherapy and occupational therapy students. The result goes parallel with recent evidences (Burgess A et al., 2017) and (Livingston B et al., 2014) by giving positive perception on Team-based learning in both groups [2, 12].

But student's preference was slightly above the neutral score in comparison to attitude \& feeling towards TBL. This is the very first time that these two groups of students are introduced to TBL. So at very initial stage of the process of 
TBL, student's preferences for TBL may not be markedly elevated from the preference for traditional teaching and learning activities as the two groups are new to this process. When considering the literature, the results of other studies in which the TBL is introduced at very first time, the selected study group shows slight preference [21]. But when the preference for TBL is assessed in groups in which TBL is ongoing process of learning, preference level is elevated [15]. So the results of the study was comparable with evidences. When considering students positive attitude $\&$ feeling towards the TBL, even though it was the initiative stage, the level of attitude $\&$ feeling stays on significant level above from natural score. Hence the attitude and feeling did not markedly affect even though in the initial stage of TBL. This result finding was comparable with literature emphasizing the fact that, positive attitude \& feeling can be established even in initial stage of any given teaching and learning activity.

When the level of preference and the attitude/ feeling were compared in two groups, there was no any significant difference. Both groups of students were in same academic year. So their academic experience, attitudes towards the academic setup, understanding on teaching and learning activities, and adaptation to the academic environment may remain at same level. So these similarities may prevent differences of perception of TBL among two groups. And also the time period they have spent in higher education prior to respective diploma goes closely in two groups. Previous educational experience shows effect in outcomes of current educational process $[11,12]$. So same level of previous higher educational exposure in two groups may prevent significant differences in preference and attitude \& feeling on TBL.

\section{Correlation between preferences and attitude $\&$ feeling}

When comparing the level of preference and the attitude/feeling, they showed several correlations. In the whole population, there was a significant positive moderate correlation among level of preference and the attitude on TBL. This result goes parallel with recent evidence on TBL [13]. When considering two groups, in occupational therapy students there was also a significant positive moderate correlation among level of preference and attitude on TBL. This result goes parallel with literature evidences emphasizing significant linear relationship between preference and attitudes/feelings education by emphasizing a linear relationship [11]. But some studies suggested there was no significant linear relationship between preference and attitudes/feelings in education as the correlation was concluded in physiotherapy student group [9]. In physiotherapy students, correlation between preference and attitude is insignificant. Female percentage is comparatively high in occupational therapy student group. When considering about the two groups as a single group, high percentage was occupied by females. But in physiotherapy students group both genders are in equal percentages. So having significant correlation among level of preference and level of attitude in occupation therapy student group in comparison to physiotherapy students may be due to that gender difference. In which males and females may have different abilities to absorb higher educational prospects [6].

Preference level in physiotherapy student group did not show signification correlation with preference level in occupational therapy students. And also attitude/feeling level in physiotherapy students did not show significant correlation with attitude/feeling level in occupational therapy students. This results finding goes comparable with recent literature in which relationship between preference and feeling/attitude was concluded [12, 13]. .But there was an insignificant negative correlation of both preference and attitudes/feeling. This may be due to comparatively high female percentage in occupational therapy student group.

Age and previous higher educational exposure did not show any significant correlation with preference and attitudes/feelings. But there was an insignificant negative correlation among age with preference and previous higher educational exposure with attitude/feeling. This result's findings were comparable with existing literature. Some literature suggested there is an effect of age in higher education [19, 22]. But some evidence suggests there is no relationship between ages in education [1]. There are less amount of studies have been done on relationship or effect of previous higher education exposure in current higher education. But some evidence suggests there was no such a significant association [20]. 


\section{Conclusion}

Team-based learning is one of the most effective learning and teaching methods. There is a positive perception on team-based learning among physiotherapy and occupational therapy student groups of batch XXXV of school of physiotherapy and occupational therapy. And also there is a significant linear relationship between student's preferences and attitudes/feelings in team-based learning.

\section{Recommendation}

1. To encourage the use of team-based learning methods in higher educational setups.

2. To do further extensive scientific studies on team-based learning and its effects.

\section{DECLARATIONS}

\section{Funding}

This research did not receive any specific grant from funding agencies in the public, commercial, or not-for-profit sectors.

\section{Conflicts of Interest}

The authors declared no potential conflicts of interest with respect to the research, authorship, and/or publication of this article.

\section{REFERENCES}

[1] Abbie-Rose Imlach, David D. Ward, Kimberley E. Stuart, Mathew J. Summers, Michael J. Valenzuela, Anna E. King, Nichole L. Saunders, Jeffrey Summers, Velandai K. Srikanth, Andrew Robinson and James C. Vickers (2017): Age is no barrier: predictors of academic success in older learners, npj Science of Learning 3(7), pp 245-251.

[2] Burgess, A., Bleasel, J., Haq, I., Roberts, C., Garsia, R., Robertson, T and Mellis, C. (2017): Team-based learning (TBL) in the medical curriculum: better than PBL? BMC Medical Education17, pp 243.

[3] Carmichael J (2009): Team-based learning enhances performance in introductory biology. J CollSci Teach 38(4), pp 54-61.

[4] Chhabra, N., Kukreja, S., Chhabra, S., Chhabra, S., Khodabux, S and Sabane, H. (2017): Team-based Learning Strategy in Biochemistry: Perceptions and Attitudes of Faculty and 1st-Year Medical Students.International Journal of Applied and Basic Medical Research 7, pp 72-S77.

[5] Chung E K, Rhee J A E, Baik Y H, and A Os (2009): The effect of team-based learning in medical ethics education. Med Teach 31(11), pp1013-101.

[6] Elizabeth Fennema and Julia Sherman (1997): Sex-Related Differences in Mathematics Achievement, Spatial Visualization and Affective Factors, American Education 14 (1), pp 51-71.

[7] Faezi, S. T., Moradi, K., GhafarRahimi Amin, A., Akhlaghi, M and Keshmiri, F (2018): The effects of team-based learning on learning outcomes in a course of rheumatology. Journal of Advances in Medical Education \& Professionalism, 6(1), pp 22-30.

[8] Frame, T. R., Gryka, R., Kiersma, M. E., Todt, A. L., Cailor, S. M and Chen, A. M. H (2016): Student Perceptions of and Confidence in Self-Care Course Concepts Using Team-based Learning, American Journal of Pharmaceutical Education, 80(3), pp 46.

[9] GüneşKılınç (2012): The Relationship Between the Learning Styles of Students and Their Attitudes Towards Social Studies Course, Procedia - Social and Behavioral Sciences55(5), pp 47-56

[10] Koohestani, H. R and Baghcheghi, N (2016): The effects of team-based learning techniques on nursing students' perception of the psycho-social climate of the classroom. Medical Journal of the Islamic Republic of Iran30, pp 437.

[11] Lana DvorkinCamiel, Amee Mistry, David Schnee, Gary Tataronis, Catherine Taglieri, Kathy Zaiken, Dhiren Patel, 
Stefanie Nigro, Susan Jacobson and Jennifer Goldman (2016): Student's Attitudes, Academic Performance and Preferences for Content Delivery in a Very Large Self-Care Course Redesign, Am J Pharm Edu 80(4)

[12] Levi Doe Kalagbor (2016): An Analysis of Factors Influencing Students' Academic Performance in Public and Private Secondary Schools in Rivers State-Nigeria, Journal of Education and Practice 7(28)

[13] Livingston, B., Lundy, M and Harrington, S (2014): Physical therapy students' perceptions of team-based learning in gross anatomy using the Team-Based Learning Student Assessment Instrument. Journal of Educational Evaluation for Health Professions11, pp 12-17.

[14] Michaelsen LK and Sweet M (2008): The essential elements of team-based learning. New Dir Teach Learn, pp. 7-27.

[15] NeenaPiyushDoshi (2017): Effectiveness of team-based learning methodology in teaching transfusion medicine to medical undergraduates in third semester: A comparative study, Asian J TransfusSci11(2). pp 87-94.

[16] Opdecam E, Everaert P, Keer H V and Buysschaert F (2013): Preferences for Team Learning and Lecture-Based Learning among First-Year Undergraduate Accounting Students, 55 (4), pp 400-432.

[17] Remington, T. L., Bleske, B. E., Bartholomew, T., Dorsch, M. P., Guthrie, S. K., Klein, K. C and Wells, T. D (2017): Qualitative Analysis of Student Perceptions Comparing Team-based Learning and Traditional Lecture in a Pharmacotherapeutics Course. American Journal of Pharmaceutical Education, 81(3), pp 76.

[18] Sheikh Salahuddi and HumayunKabirTalukder (2017): Influence of Socio-Demographic Characteristics on Academic Performance of Medical Students, Bangladesh Journal of Medical Education 8(2), pp 18-27.

[19] RashmiKusurkar, CasKruitwagen, Olle ten Cate, and GerdaCroiset (2010): Effects of age, gender and educational background on strength of motivation for medical school, Adv Health SciEduc Theory Pract 15(3), pp 303-313.

[20] Siewfoenng, RazimiZakaria, See May Lai and Gary J Confessor (2016): A study of time use and academic achievement among secondary-school students in the state of Kelantan, Malaysia, International Journal of Adolescence and Youth 21(4)

[21] Tracy R. Frame, Stephanie M. Cailor, Rebecca J. Gryka, Aleda M. Chen, Mary E. Kiersma and Lorin Sheppard (2015): Student Perceptions of Team-based Learning vs Traditional Lecture-based Learning, Am J Pharm Educ 79(4), pp 51.

[22] Wilkinson T.J., Wells J.E and Bushnell JA (2004): Are differences between graduates and undergraduates in a medical course due to age or prior degree? Med Educ 38(11), pp. 1141-6. 